\title{
A survey of sedation practices for colonoscopy in Canada
}

\author{
Peter Porostocky MD FRCPC 1 , Naoki Chiba MD MSc FRCPC ${ }^{2}$, Palma Colacino ${ }^{3}$, \\ Dan Sadowski MD FRCPC ${ }^{4}$, Harminder Singh MD MPH FRCPC 1,5
}

\begin{abstract}
P Porostocky, N Chiba, P Colacino, D Sadowski, H Singh. A survey of sedation practices for colonoscopy in Canada. Can J Gastroenterol 2011;25(5):255-260.
\end{abstract}

BACKGROUND: There are limited data regarding the use of sedation for colonoscopy and concomitant monitoring practices in different countries.

METHODS: A survey was mailed to 445 clinician members of the Canadian Association of Gastroenterology and 80 members of the Canadian Society of Colon and Rectal Surgeons in May and June 2009. RESULTS: Sixty-five per cent of Canadian Association of Gastroenterology members and 69\% of Canadian Society of Colon and Rectal Surgeons members responded with the full survey. Most endoscopists reported using sedation for more than $90 \%$ of colonoscopies. The most common sedation regimen was a combination of midazolam and fentanyl. Propofol, either alone or with another drug, was used in $12 \%$ of cases. A higher proportion (94\%) of adult gastroenterologists who routinely used propofol were highly satisfied compared with those using other sedative agents $(45 \% ; \mathrm{P}<0.001)$. Fifty per cent of adult gastroenterologists and $29 \%$ of surgeons who were not currently using propofol expressed interest in starting to use it for routine colonoscopies. Only a single nurse was present in the endoscopy room during colonoscopy performed by two-thirds of the endoscopists.

CONCLUSIONS: Results of the present survey suggest that gastroenterologists in Canada use sedation for colonoscopy in more than $90 \%$ of their patients. There was higher satisfaction among gastroenterologists who used propofol routinely for all colonoscopies. Most endoscopy rooms were staffed by a single nurse, which may limit further increases in the use of propofol. Further studies are needed to determine optimal staffing of endoscopy units with and without the use of propofol. Sedation practices of general surgery endoscopists need to be evaluated.

Key Words: Canada; Colonoscopy; Endoscopy room staffing; Propofol; Sedation

Sedation for colonoscopy can enhance the performance of the pro$\checkmark$ cedure, leading to higher colonoscopy completion rates and colonic polyp detection rates (1). However, the use of sedation for endoscopy is resource intensive. In the United States (US), it has been estimated that sedation accounts for $75 \%$ of patient time in the endoscopy unit and $40 \%$ of the procedure costs (2).

There is wide variation in the use of sedation for endoscopy globally. While almost all colonoscopies in the US and the United Kingdom are performed with sedation, some centres in continental Europe rarely use it for colonoscopy (3-5). The standard monitoring protocols used during colonoscopy also vary markedly among centres (4).

\section{Un sondage sur les pratiques de sédation avant la coloscopie au Canada}

HISTORIQUE : On possède peu de données sur l'utilisation de la sédation avant une coloscopie et les pratiques de surveillance concomitantes dans les divers pays.

MÉTHODOLOGIE : Un sondage a été posté aux 445 membres cliniciens de l'Association canadienne de gastroentérologie et aux 80 membres de la Société canadienne des chirurgiens du côlon et du rectum en mai et juin 2009.

RÉSULTATS : Soixante-cinq pour cent des membres de l'Association canadienne de gastroentérologie et $69 \%$ de ceux de la Société canadienne des chirurgiens du côlon et du rectum ont répondu à la totalité du sondage. La plupart des endoscopistes déclarent utiliser la sédation dans plus de $90 \%$ des coloscopies. La posologie de sédation la plus courante était une association de midazolam et de fentanyl. Le propofol, seul ou en combinaison avec un autre médicament, était utilisé dans $12 \%$ des cas. Une plus forte proportion (94\%) des gastroentérologues pour adultes qui utilisaient régulièrement le propofol étaient très satisfaits par rapport à ceux qui utilisaient d'autres sédatifs (45\%; $\mathrm{P}<0,001)$. Cinquante pour cent des gastroentérologues pour adultes et $29 \%$ des chirurgiens qui n'administraient alors pas le propofol se sont montrés intéressés à y recourir pour les coloscopies habituelles. Pour les deux tiers des endoscopistes, une seule infirmière était présente dans la salle d'endoscopie pendant la coloscopie.

CONCLUSIONS : D'après les résultats du présent sondage, les gastroentérologues du Canada recourent à la sédation en prévision de la coloscopie auprès de plus de $90 \%$ de leurs patients. Les gastroentérologues qui utilisaient systématiquement le propofol avant toutes les coloscopies affichaient un plus fort taux de satisfaction. La plupart des salles d'endoscopie étaient dotées d'une seule infirmière, ce qui peut limiter l'augmentation du recours au propofol. D'autres études s'imposent pour déterminer la dotation en personnel optimale des unités d'endoscopie avec ou sans le recours au propofol. Les pratiques de sédation des endoscopistes de chirurgie générale ont besoin d'être évaluées.

Propofol is increasingly being used for sedation during colonoscopy because it shortens recovery time after the procedure and can enhance patient satisfaction $(6,7)$. However, in many countries, propofol is usually administered by an anesthetist (or a nurse anesthetist) and, thus, can significantly add to the cost of the procedure (3). In fact, recently, nongastroenterological societies in the US have arbitrarily decreed that propofol can only be given by anesthesia personnel - a position being challenged by the American College of Gastroenterology, American Society for Gastrointestinal Endoscopy (ASGE), American Association for the Study of Liver Diseases and American Gastroenterological Association.

There are limited data regarding the use of sedation for colonoscopy and concomitant monitoring practices in Canada. There are an

${ }^{1}$ Department of Internal Medicine, Section of Gastroenterology, University of Manitoba, Winnipeg, Manitoba; ${ }^{2}$ Division of Gastroenterology, McMaster

University, Hamilton, and Guelph General Hospital, Guelph; ${ }^{3}$ Canadian Association of Gastroenterology, Oakville, Ontario; ${ }^{4}$ Division of

Gastroenterology, Royal Alexandra Hospital, University of Alberta, Edmonton, Alberta; ${ }^{5}$ Community Health Sciences, University of Manitoba,

Winnipeg, Manitoba

Correspondence: Dr Harminder Singh, Department of Internal Medicine, Section of Gastroenterology, University of Manitoba, 805-715 McDermot

Avenue, Winnipeg, Manitoba R3E 3P4. Telephone 204-480-1311, fax 204-789-3972, e-mail singh@cc.umanitoba.ca

Received for publication May 26, 2010. Accepted October 18, 2010 
TABLE 1 Demographics of the survey respondents and clinicians in
the Canadian Association of Gastroenterology (CAG)
membership database

\begin{tabular}{|c|c|c|c|c|}
\hline & \multicolumn{3}{|c|}{ Physician specialty } & \multirow{2}{*}{$\begin{array}{c}\text { Clinicians in the } \\
\text { CAG database }{ }^{*} \\
(n=404)\end{array}$} \\
\hline & $\begin{array}{l}\text { Adult GI } \\
(n=246)\end{array}$ & $\begin{array}{c}\text { Surgery } \\
(n=55)\end{array}$ & $\begin{array}{l}\text { Ped GI } \\
(n=32)\end{array}$ & \\
\hline \multicolumn{5}{|l|}{ Location of primary practice } \\
\hline Atlantic Canada & $18(7)$ & $5(9)$ & $2(6)$ & $25(6)$ \\
\hline Quebec & $45(18)$ & $10(18)$ & $7(22)$ & $68(17)$ \\
\hline Ontario & $111(45)$ & $21(38)$ & $13(41)$ & $181(45)$ \\
\hline Manitoba/Saskatchewan & $13(5)$ & $4(7)$ & $1(3)$ & $17(4)$ \\
\hline Alberta & $36(15)$ & $9(16)$ & $5(16)$ & $68(17)$ \\
\hline British Columbia & $23(9)$ & $6(11)$ & $3(10)$ & $43(11)$ \\
\hline Yukon/Nunavut/NWT & $0(0)$ & $0(0)$ & $0(0)$ & $2(1)$ \\
\hline \multicolumn{5}{|l|}{ Population of practice city } \\
\hline Small $(<100,000)$ & $21(9)$ & $2(4)$ & $0(0)$ & - \\
\hline $\begin{array}{l}\text { Medium (100,000 - } \\
1 \text { million) }\end{array}$ & $129(52)$ & $26(47)$ & $12(38)$ & - \\
\hline Large (>1 million) & $96(39)$ & $27(49)$ & $20(63)$ & - \\
\hline \multicolumn{5}{|l|}{ Years in practice } \\
\hline$<3$ & $26(11)$ & $6(11)$ & $3(10)$ & - \\
\hline $3-10$ & $58(24)$ & $19(35)$ & $10(32)$ & - \\
\hline$>10-30$ & $122(50)$ & $25(45)$ & $18(56)$ & - \\
\hline$>30$ & $40(16)$ & $5(9)$ & $0(0)$ & - \\
\hline \multicolumn{5}{|l|}{ Sex } \\
\hline Male & $199(81)$ & $46(84)$ & $16(50)$ & $313(77)$ \\
\hline \multicolumn{5}{|l|}{ Primary site of practice } \\
\hline University hospital & $125(51)$ & $40(73)$ & $29(91)$ & 237 (59) \\
\hline Community hospital & $107(43)$ & $13(24)$ & $3(9)$ & $167(41)$ \\
\hline $\begin{array}{l}\text { Free-standing endoscopy } \\
\text { unit }\end{array}$ & $14(6)$ & $2(4)$ & $0(0)$ & $\neq$ \\
\hline
\end{tabular}

Data presented as $n$ (\%). *The demographics in the CAG membership database were obtained several months after the initial mailing; ${ }^{\dagger}$ There were no significant differences among adult gastroenterologist respondents and all clinicians in the CAG database in terms of location of primary practice $(P=0.90)$, sex $(P=0.06)$ or primary site of practice $(P=0.24)$; ${ }^{\ddagger}$ The CAG membership database does not include free-standing endoscopy units as a site of practice. GI Gastroenterology; NWT Northwest Territories; Ped Pediatric

increasing number of free-standing endoscopy units in Canada (particularly in the province of Ontario), but it is not known whether the practice of sedation is any different at these units. A previous study from Ontario (8) found a higher rate of new/missed colorectal cancers after performance of endoscopy at the free-standing endoscopy units. The authors speculated that it was due to the use of less sedation and, hence, a greater number of incomplete colonoscopies at the free-standing endoscopy units. In addition, we are not aware of data regarding endoscopy room staffing patterns in units in different jurisdictions.

We conducted a survey to determine Canadian endoscopists' use of sedation, concomitant monitoring practices and endoscopy room staffing patterns during colonoscopy. The survey also aimed to determine the level of satisfaction endoscopists had with currently available sedative agents.

\section{METHODS}

A four-page, 25-item multiple-choice survey was developed by the authors. The survey was first distributed to the members of the Canadian Association of Gastroenterology (CAG) Clinical Affairs Committee and gastroenterologists at the University of Manitoba (Winnipeg, Manitoba) to establish content and face validity, and for pilot testing.
The self-addressed, prestamped final version of the survey was mailed to all 445 clinician members of the CAG and all 80 members of the Canadian Society of Colon and Rectal Surgeons (CSCRS) in May 2009. Gastroenterology fellows, surgical residents and members not practicing in Canada were not included. A cover letter explaining the purpose of the study, a request for participation in the survey and an abbreviated nonresponse form (for those who did not wish to participate in the full survey or did not perform colonoscopy) accompanied the sedation survey. To improve the response rate, nonrespondents were mailed the survey again if they failed to respond with the full survey or with the nonresponse form within four weeks of the initial mailing. The mailing was performed by the administrative office staff of the CAG and CSCRS. To maintain anonymity of the respondents, each survey was assigned a unique code and the responses remained anonymous to the study investigators. The unique code was used only by the administrative office staff of the CAG and CSCRS to direct the second mailing to nonrespondents.

Components of the survey included the respondents' demographics, choice of sedative agents (including dose), satisfaction with sedative agents (measured on an ordinal scale from 1 to 10, with 10 representing complete satisfaction), differences in the endoscopist's sedation practice when colonoscopy was performed by an endoscopist at more than one practice site, use of propofol, endoscopy room staffing and monitoring of sedated patients.

A spreadsheet (Excel [Microsoft Corporation, USA]) was used to collate the survey responses. Standard descriptive statistics were used to describe the response frequency. Survey results are reported separately for adult gastroenterologists, surgeons and pediatric gastroenterologists. The $\chi^{2}$ test was used to compare the categorical variables and a two-sided $\mathrm{P}<0.05$ was considered to be statistically significant. The demographic characteristics of the CAG respondents were compared with the aggregate national demographic data from the CAG clinician membership database. To ascertain geographical variations across the country, a comparison was performed between the sedation practices in Ontario (the largest province in Canada and the province with the largest number of free-standing endoscopy units) and the rest of the country.

The present study was approved by the University of Manitoba's Health Research Ethics Board.

\section{RESULTS}

Sixty five per cent of CAG members $(n=288)$ and $69 \%$ of CSCRS members $(n=55)$ responded with the full survey. Twelve of the 13 individuals who returned the nonresponse form did not perform colonoscopy.

\section{Demographics (Table 1)}

Of the CAG respondents, $85 \%$ were adult gastroenterologists and $11 \%$ were pediatric gastroenterologists. The remaining $4 \%$ of the CAG respondents who self-declared their primary specialty as another specialty such as internal medicine or hepatology, were not included in the analysis. Geographically, the distribution of CAG respondents was almost identical to that of CAG members in Canada, with most practicing in the provinces of Ontario (45\%), Quebec (18\%) or Alberta (15\%). The majority of CSCRS respondents (84\%) were colorectal surgeons, $15 \%$ were general surgeons and $1 \%(n=1)$ were surgical oncologists. In terms of geographical distribution, surgeons and pediatric gastroenterologists followed a pattern similar to the adult gastroenterologists. The majority of adult endoscopists (gastroenterologists and surgeons) were men (84\%), and practicing for between 10 and 30 years (49\%). Pediatric gastroenterologists had an equal distribution between men and women. Most adult endoscopists practiced within a medium-sized $(51 \%)$ or large metropolitan area $(41 \%)$. The primary site of practice was a university-affiliated hospital for the majority of the adult endoscopists (55\%). More than $90 \%$ of pediatric gastroenterologists practiced at a university hospital.

Routine sedation practices (Table 2)

Most adult endoscopists (92\%) decided the dose, frequency and timing of the administration of the sedative agents. However, for a large 
TABLE 2

Routine colonoscopy sedation practices of Canadian endoscopists

\begin{tabular}{lccc}
\hline & \multicolumn{3}{c}{ Physician specialty } \\
\cline { 2 - 4 } & Adult GI & Surgery & Ped GI \\
\hline Primary responsibility for administration of the sedative agents \\
Endoscopist & $218(91)$ & $53(96)$ & $12(38)$ \\
Endoscopy nurse & $9(4)$ & $0(0)$ & $6(19)$ \\
Anesthetist & $12(5)$ & $2(4)$ & $14(44)$ \\
Similar use of sedation at different facilities by the endoscopists \\
performing colonoscopy at more than one site \\
Yes & $56(57)$ & $12(71)$ & $2(100)$ \\
No & $33(43)$ & $5(29)$ & $0(0)$
\end{tabular}

Proportion of colonoscopy cases for which intravenous sedation was used at different practice sites

At university hospitals

$\begin{array}{lccc}<50 & 0(0) & 3(7) & 1(4) \\ 50-75 & 3(2) & 0(0) & 1(4) \\ >75-90 & 15(11) & 4(10) & 0(0) \\ >90 & 116(87) & 35(83) & 25(93) \\ \text { At community hospitals } & & \\ <50 & 0(0) & 0(0) & 0(0) \\ 50-75 & 1(1) & 0(0) & 1(50) \\ >75-90 & 5(4) & 0(0) & 0(0) \\ >90 & 107(95) & 13(100) & 1(50) \\ \text { At free-standing endoscopy units } & & & \\ <50 & 2(3) & 0(0) & 0(0) \\ 50-75 & 2(3) & 1(10) & 0(0) \\ >75-90 & 3(5) & 0(0) & 0(0) \\ >90 & 55(89) & 9(90) & 0(0)\end{array}$

Most commonly used class of sedative agents

Combination of a benzodiazepine and a $\quad 192(79) \quad 49(92) \quad 10$ (31)

narcotic

A benzodiazepine alone

Propofol alone

Propofol, in combination with another agent

Others*

Usual total dose of midazolam, mg

\begin{tabular}{|c|c|c|c|}
\hline$<3$ & $63(32)$ & $17(34)$ & $3(23)$ \\
\hline $3-5$ & $128(64)$ & $31(62)$ & $10(77)$ \\
\hline $6-10$ & $8(4)$ & $1(2)$ & $0(0)$ \\
\hline$>10$ & $0(0)$ & $1(2)$ & $0(0)$ \\
\hline \multicolumn{4}{|l|}{ Usual total dose of fentanyl, mg } \\
\hline$<25$ & $2(1)$ & $0(0)$ & $1(11)$ \\
\hline $25-50$ & $25(12)$ & $13(27)$ & $1(11)$ \\
\hline $51-100$ & $155(76)$ & $33(69)$ & $6(67)$ \\
\hline $101-150$ & $23(11)$ & $2(4)$ & $1(11)$ \\
\hline$>150$ & $0(0)$ & $0(0)$ & $0(0)$ \\
\hline \multicolumn{4}{|l|}{ Jsual total dose of propofol, $g$} \\
\hline$<40$ & $4(11)$ & $0(0)$ & $1(5)$ \\
\hline $40-80$ & $3(8)$ & $0(0)$ & $0(0)$ \\
\hline $81-160$ & $6(17)$ & $0(0)$ & $0(0)$ \\
\hline $161-240$ & $2(6)$ & $0(0)$ & $0(0)$ \\
\hline$>240$ & $0(0)$ & $0(0)$ & $0(0)$ \\
\hline $\begin{array}{l}\text { Did not know because administered by } \\
\text { another provider }\end{array}$ & $21(58)$ & $3(100)$ & 19 (95) \\
\hline \multicolumn{4}{|l|}{ Routine supplementary oxygen } \\
\hline les & $153(65)$ & $27(49)$ & $23(72)$ \\
\hline No & $84(35)$ & $28(50)$ & $9(28)$ \\
\hline
\end{tabular}

Data presented as $n$ (\%). *Other agents used included ketamine, promethazine, hyoscine and buscopan. GI Gastroenterology; Ped Pediatric
TABLE 3

Monitoring of patients and endoscopy room staffing during colonoscopy and endoscopist satisfaction with available sedative agents for routine colonoscopy

\begin{tabular}{|c|c|c|c|}
\hline & \multicolumn{3}{|c|}{ Physician specialty } \\
\hline & Adult GI & Surgery & Ped GI \\
\hline \multicolumn{4}{|l|}{ Routine monitoring } \\
\hline $\mathrm{BP}, \mathrm{HR}$ and oxygen saturation & $213(88)$ & $40(75)$ & $14(44)$ \\
\hline $\mathrm{BP}, \mathrm{HR}$, oxygen saturation and EKG & $26(11)$ & $7(13)$ & $9(28)$ \\
\hline $\begin{array}{l}\text { BP, HR, oxygen saturation, EKG and } \\
\text { capnography }\end{array}$ & $1(0)$ & $0(0)$ & $5(16)$ \\
\hline $\begin{array}{l}\text { BP, HR, oxygen saturation and } \\
\text { capnography }\end{array}$ & $1(0)$ & $0(0)$ & $0(0)$ \\
\hline Other* & $4(2)$ & $6(12)$ & $4(12)$ \\
\hline \multicolumn{4}{|l|}{ Personnel in endoscopy room } \\
\hline One registered nurse alone & $161(65)$ & $34(64)$ & $4(12)$ \\
\hline Two registered nurses & $29(12)$ & $4(8)$ & $6(19)$ \\
\hline $\begin{array}{l}\text { One registered nurse and another } \\
\text { assistant }^{\dagger} \text { (including resident) }\end{array}$ & $21(9)$ & $13(25)$ & $16(50)$ \\
\hline One assistant ${ }^{\dagger}$ alone (no registered nurse) & $7(3)$ & $1(2)$ & $1(3)$ \\
\hline Another physician (including anesthetist) & $28(11)$ & $1(2)$ & $5(16)$ \\
\hline \multicolumn{4}{|c|}{ Endoscopist satisfaction with currently available sedative agents ${ }^{\ddagger}$} \\
\hline 9 to 10 & $117(49)$ & $38(70)$ & $21(70)$ \\
\hline 7 to 8 & $108(45)$ & $14(25)$ & $6(20)$ \\
\hline 5 to 6 & $11(5)$ & $3(5)$ & $3(10)$ \\
\hline$\leq 4$ & $3(0)$ & $0(0)$ & $0(0)$ \\
\hline
\end{tabular}

Data presented as $n$ (\%). *Six surgeons, four adult gastroenterologists and four pediatric gastroenterologists did not report monitoring of heart rate and/or oxygen saturation; ${ }^{\dagger}$ Assistants included nursing or endoscopy assistant or licensed practical nurse; ${ }^{\ddagger}$ On a scale of 1 to 10 , with $10=$ highest satisfaction and 1 = lowest satisfaction. BP Blood pressure; EKG Electrocardiography; GI Gastroenterology; HR Heart rate; Ped Pediatric

proportion of pediatric gastroenterologists (44\%), an anesthetist had the primary responsibility for administering the sedative agent $(\mathrm{P}<0.001$ [comparison with adult endoscopists]). Among adult endoscopists who performed colonoscopies at more than one facility, the same sedative drugs and dosages were used at the different facilities by twothirds of the endoscopists. A higher proportion of adult endoscopists used intravenous sedation for more than $90 \%$ of colonoscopies performed by them at the community hospitals (95\%), than at the university hospitals $(87 \%)$ or free-standing endoscopy units $(89 \%)(\mathrm{P}=0.03)$.

A combination of a benzodiazepine and a narcotic was used by most of the adult endoscopists (79\%), while propofol with or without another agent was used by a small minority $(12 \%)$. The majority of pediatric gastroenterologists $(59 \%)$ used propofol alone or in combination with another sedative agent. The most commonly used sedation regimen was a combination of midazolam and fentanyl by the adult gastroenterologists $(55 \%)$ and surgeons ( $81 \%)$, followed by a combination of diazepam and fentanyl (adult gastroenterologists: $9 \%$; surgeons: $4 \%$ ). The most commonly used total dose of midazolam was $3 \mathrm{mg}$ to $5 \mathrm{mg}$, and $50 \mu \mathrm{g}$ to $100 \mu \mathrm{g}$ of fentanyl. Most endoscopists were not able to report the amount of propofol used because it was administered by another provider.

Supplementary oxygen was provided for all colonoscopies performed by $65 \%$ of adult endoscopists and $72 \%$ of pediatric gastroenterologists.

Patient monitoring during colonoscopy (Table 3)

Almost all endoscopists reported monitoring of patients' heart rate and oxygen saturation by pulse oximetry during most of the colonoscopies performed by them. Eleven per cent of adult endoscopists and $44 \%$ of pediatric gastroenterologists reported routine use of continuous electrocardiogram monitoring during colonoscopy. Only two adult endoscopists and five pediatric gastroenterologists reported routine use of capnography. Almost two-thirds of adult endoscopists had only one registered nurse present in the endoscopy room during a colonoscopy. 


\section{TABLE 4}

Use of propofol for colonoscopy in Canada reported by survey respondents

\begin{tabular}{lccc}
\hline & \multicolumn{3}{c}{ Physician specialty } \\
\cline { 2 - 4 } & Adult GI & Surgery & Ped GI \\
\hline Use of propofol for routine colonoscopies & & & \\
Yes & $32(13)$ & $2(4)$ & $21(66)$ \\
No & $209(87)$ & $53(97)$ & $11(34)$
\end{tabular}

Primary decision maker for dose, timing and frequency of administration of propofol

$\begin{array}{lccc}\text { Endoscopist } & 10(11) & 3(27) & 0(0) \\ \text { Endoscopy nurse } & 2(2) & 0(0) & 0(0) \\ \text { Anesthetist } & 79(84) & 8(73) & 25(93) \\ \text { Anesthesiology nurse } & 1(1) & 0(0) & 0(0) \\ \text { Other physician } & 2(2) & 0(0) & 2(7) \\ \text { Method of administration of propofol } & & & \\ \text { Continuous infusion only } & 5(5) & 0(0) & 4(15) \\ \text { Bolus administration only } & 53(56) & 6(67) & 4(15) \\ \text { Continuous infusion with intermittent boluses } & 13(14) & 3(33) & 13(50) \\ \text { Patient-controlled sedation } & 0(0) & 0(0) & 0(0) \\ \text { Survey respondents not aware because } & 24(26) & 0(0) & 5(19)\end{array}$

administered by another provider

Propofol used as a single agent or in combination with another agent

$\begin{array}{lrrr}\text { Single } & 32(33) & 3(38) & 5(19) \\ \text { Combination } & 33(34) & 4(50) & 3(12) \\ \text { Survey respondents not aware because } & 32(33) & 1(13) & 18(69)\end{array}$

administered by another provider

Duration of propofol use for any colonoscopies, years

$\begin{array}{lccc}<1 & 12(14) & 2(22) & 0(0) \\ 1-2 & 23(26) & 2(22) & 0(0) \\ >2-5 & 35(40) & 4(44) & 5(22) \\ >5 & 18(20) & 1(11) & 18(78)\end{array}$

Endoscopist's desire to start using propofol for routine colonoscopy, if not currently using

$\begin{array}{llll}\text { Yes } & 98(51) & 15(29) & 4(50) \\ \text { No } & 96(50) & 36(71) & 4(50)\end{array}$

Endoscopists' opinion as to who should be responsible for the use of propofol

$\begin{array}{lccc}\text { Endoscopist } & 89(38) & 17(35) & 2(6) \\ \text { Endoscopy nurse } & 9(4) & 0(0) & 0(0) \\ \text { Anesthetist } & 91(39) & 26(52) & 28(85) \\ \text { Anesthesiology nurse/assistant } & 37(16) & 7(14) & 2(6) \\ \text { Other* } & 6(3) & 0(0) & 1(3)\end{array}$

Data presented as $n$ (\%). *Other responses included a physician other than the endoscopist or an anesthetist, and respondents not having decided to date. CAG Canadian Association of Gastroenterology; GI Gastroenterology; Ped Pediatric

Endoscopists' satisfaction with currently available sedative agents for colonoscopy (Table 3)

On the 10-point ordinal scale, approximately one-half of adult gastroenterologists, $70 \%$ of surgeons and $70 \%$ of pediatric gastroenterologists reported a satisfaction level of 9 or 10 with the sedative agents used by them. However, only 5\% of adult gastroenterologists and surgeons scored 6 or lower. A higher proportion (94\%) of 32 adult gastroenterologists using propofol routinely for all cases were highly satisfied (satisfaction score 9 or 10) compared with those using other sedative agents $(45 \% ; \mathrm{P}<0.001)$.

Use of propofol for colonoscopy (Table 4)

Of the endoscopists who used propofol, administration for almost all cases was reported by the majority of pediatric gastroenterologists (54\%) and only $17 \%$ of adult gastroenterologists. The use of propofol
TABLE 5

Endoscopists' choice of sedative agent for their own colonoscopy

\begin{tabular}{llll}
\hline & \multicolumn{3}{c}{ Physician specialty } \\
\cline { 2 - 4 } & Adult GI Surgery & Ped GI \\
\hline No sedation & $20(8)$ & $3(6)$ & $1(3)$ \\
No sedation at start of procedure* & $47(19)$ & $9(17)$ & $3(10)$ \\
Combination of a benzodiazepine and a narcotic & $70(28)$ & $28(54)$ & $5(17)$ \\
Propofol alone & $32(13)$ & $2(4)$ & $8(28)$ \\
Propofol in combination with another agent(s) & $54(22)$ & $6(12)$ & $12(41)$ \\
Other $^{\dagger}$ & $19(8)$ & $3(6)$ & $0(0)$ \\
\hline
\end{tabular}

Data presented as $n$ (\%). *Sedation only if colonoscopy not tolerated without sedation; ${ }^{\dagger}$ Other choices included a narcotic alone, a benzodiazepine alone or no preferences. GI Gastroenterology; Ped Pediatric

for routine colonoscopies was highest among pediatric gastroenterologists (66\%) and was reported by $13 \%$ of adult gastroenterologists. Interestingly, in Ontario, 23\% of adult gastroenterologists used propofol for routine colonoscopy, compared with $5 \%$ in the rest of the country $(\mathrm{P}<0.001)$. The use of propofol for routine colonoscopy was more common among adult gastroenterologists whose primary site of practice was at a community hospital $(20 \%)$ or a free-standing endoscopy unit $(21 \%)$ than among those practising at university hospitals (5\%) $(\mathrm{P}=0.002)$. When propofol was used, the dose and frequency was determined by an anesthetist for the colonoscopies performed by most (83\%) of the adult endoscopists. The majority of adult endoscopists (57\%) who used propofol reported solely bolus administration. An equal proportion reported the use of propofol as a single agent or in combination with another agent.

Whereas approximately one-half of the adult gastroenterologists not currently using propofol expressed an interest in use of propofol for routine colonoscopies, $29 \%$ of surgeons were similarly interested in its use $(\mathrm{P}=0.007)$. The majority $(54 \%)$ of adult endoscopists believed that an anesthetist or an anesthesiology nurse (or assistant) should be responsible for the use of propofol during routine colonoscopy.

Choice of sedative agent for endoscopists' own colonoscopy (Table 5) Eight per cent of all adult endoscopists would prefer to undergo their own colonoscopy without any sedation. Another 19\% would prefer to have the procedure started without sedation and sedatives used only if the procedure was not tolerated. Whereas only one-third of the adult endoscopists preferred the use of propofol (with or without another agent), more than two-thirds of pediatric gastroenterologists indicated a preference for propofol $(\mathrm{P}<0.001)$.

Comparison of sedation practices in Ontario with the rest of Canada

In Ontario, $23 \%$ of adult gastroenterologists used propofol for routine colonoscopy, compared with $5 \%$ in the rest of the country $(\mathrm{P}<0.001)$. Likely reflective of this higher rate of use of propofol in Ontario, anesthesiologists were involved during colonoscopy for a higher proportion of procedures performed by adult gastroenterologists in Ontario than in the rest of Canada ( $10 \%$ versus $5 \% ; \mathrm{P}=0.04$ ). There were no other differences in sedation practices in Ontario compared with the rest of the country (data not shown).

\section{DISCUSSION}

The results of our survey, consisting of responses from 288 members of the CAG and 55 members of the CSRCS, provide Canadian national data on the use of sedation for colonoscopy and concomitant monitoring practices. Information regarding the satisfaction of endoscopists with current sedative agents was also obtained. With $69 \%$ of CAG members responding to our survey, the demographics of our respondents were found to be very similar to those disclosed by CAG - the majority being men, practicing in a university- or teaching-based hospital, and 
based in Ontario, Alberta or Quebec. Hence, the CAG respondents were likely representative of all CAG clinician members.

An overwhelming majority of the respondents used intravenous sedation for most colonoscopies. This is consistent with the recommendations from Cancer Care Ontario's Colonoscopy Standards Expert Panel (9), which state that sedation should be offered to all patients undergoing colonoscopy. The Panel concluded that sedation leads to better outcomes in terms of greater patient cooperation, less patient memory of discomfort, reduction in reported pain and increase in patient tolerance of the procedure.

We found a lower use of intravenous sedation for colonoscopy at the free-standing endoscopy units than at the community hospitals. This finding may explain the higher rate of incomplete colonoscopy examinations and new/missed colorectal cancers found after colonoscopy at the free-standing endoscopy units in previous studies $(8,10)$. Although the relationship between use of sedation and rate of new/ missed colorectal cancers needs to be directly evaluated in additional studies, a previous study (1) suggested that the use of sedation can lead to higher colonoscopy completion rates and colonic polyp detection rates - surrogate markers of rates of subsequent new/missed colorectal cancers $(11,12)$. However, although we found lower use of sedation at the university hospitals, the same previous studies found no difference in outcomes for procedures performed at these facilities. These seemingly contradictory findings may be partially explained by the differences in the endoscopists practicing at university hospitals versus those at community hospitals or free-standing endoscopy units, and/or other systematic practice differences among the sites (eg, anecdotally, some university hospitals have longer slating times for each colonoscopy). We believe that individual free-standing endoscopy units can provide excellent care, but there is a need for more standardization for the care provided among different endoscopy units.

More than $80 \%$ of the respondents in the current survey used a combination of a benzodiazepine and a narcotic, of which midazolam and fentanyl were the most popular choice. This use pattern was similar to that reported in the US (3), where more than $98 \%$ of colonoscopies are performed with intravenous sedation and more than three-quarters with a benzodiazepine and narcotic combination midazolam and fentanyl being the most common. In contrast, fewer (only 76\%) Swiss gastroenterologists used sedation for colonoscopy for more than $75 \%$ of cases (13). The usual doses of midazolam and fentanyl used by the respondents were well within the range recommended in the US (less than $6 \mathrm{mg}$ of midazolam and less than $200 \mu \mathrm{g}$ of fentanyl) (14) or in the UK (less than $5 \mathrm{mg}$ of midazolam and less than $100 \mu \mathrm{g}$ of fentanyl) (15). We are not aware of similar Canadian guidelines for dosage of sedative agents for endoscopy.

We found that $13 \%$ of gastroenterologist respondents used propofol for routine colonoscopies, mostly administered by anesthesiologists. Propofol is used more frequently for colonoscopies performed in facilities other than the university hospitals. Interestingly, a geographical variation in practice was seen, with a higher proportion $(23 \%)$ of respondents from Ontario using propofol for routine colonoscopies compared with $5 \%$ in the rest of the country. The use pattern for Ontario in our study was similar to that recently reported by Alharbi et al (16) from an analysis of Ontario's physicians' billing claims database. They found that 19\% of colonoscopies in 2005 in Ontario were performed with the assistance of anesthesiologists, which was used as a surrogate marker of the extent of propofol use. The similarity of the findings in the two studies provides face validity for our study.

The proportion of respondents (12\%) in Canada in the current survey who used propofol was much lower than the $26 \%$ reported in a survey of US gastroenterologists in 2004 (3). However, the involvement of anesthesiologists was similar to that in the US survey, in which in most instances (88\%) propofol administration was directed by an anesthetist. There are obviously tremendous cost implications of this practice in both countries, especially when position statements from gastroenterology societies in both countries $(17,18)$ concluded that propofol can be safely administered by trained endoscopists.
We found that a higher proportion of adult gastroenterologists who used propofol routinely for all cases were highly satisfied compared with those using other agents. Approximately one-half of the gastroenterologists not currently using propofol would like to start using it. However, as much as Canadian endoscopists want to use propofol, and are as highly satisfied as they are with the use of the drug, a discordance remains because only one-third of adult endoscopists desired the use of the drug by itself or in combination for their own colonoscopy.

Both the CAG and the ASGE recommend that an individual in the endoscopy suite, whether an anesthetist or nurse, be solely dedicated to the monitoring of the patient if propofol is being used $(18,19)$. Our survey showed that two-thirds of adult endoscopists in Canada have only one nurse present in the endoscopy room during colonoscopy. Thus, if the CAG and the ASGE position statements were followed, wider implementation of propofol use would demand additional resources, resulting in increased costs to many health regions/hospitals because an additional individual would be required for cases involving propofol.

We are not aware of any studies comparing outcomes with different staffing patterns in endoscopy rooms. However, there is one study (involving 27,000 patients) from a group in Switzerland (20) experienced with the use of propofol that reported an endoscopy team consisting of one physician endoscopist and one endoscopy nurse can safely administer propofol sedation for gastrointestinal endoscopy. The optimal staffing of endoscopy rooms (even in the setting of traditional sedative agents - narcotics and benzodiazepines) needs further study because there are huge cost implications with the number of health care providers in the endoscopy room. Anecdotally, administrators of some endoscopy units with more than one nurse in the endoscopy room are currently in the process of reducing staffing levels in their units purely as a cost-saving measure. We would caution against random reduction in endoscopy room staffing without concomitant careful evaluation of patient and procedural outcomes with different patterns of staffing.

Both the CAG and the ASGE recommend the use of pulse oximetry, blood pressure, continuous electrocardiogram and heart rate monitoring for patients receiving propofol $(18,19)$. Although more than $86 \%$ of adult endoscopists in our study used blood pressure and heart rate monitoring, and pulse oximetry for all colonoscopies, less than $11 \%$ used continuous electrocardiogram monitoring and less than $1 \%$ used capnography. Supplementary oxygen was provided for all colonoscopies performed by only two-thirds of the adult endoscopists. Thus, wider use of propofol, if the current guidelines are adhered to, will involve increased resource use and costs for monitoring during sedation for most endoscopy units.

Our study has many limitations. It was survey based and, hence, prone to nonresponse bias. However, the demographics of the gastroenterologist respondents were similar to those of the clinician membership of the CAG. All surveys are also subject to recall bias; however, there are no national or provincial databases in Canada that capture the information collected in the present survey. A Canadian system, similar to the Clinical Outcomes Research Initiative in the US, would provide valuable information. We have recommended that the CAG explore the feasibility of introducing such a system nationwide in Canada, which could also lead to an improvement in endoscopy reporting and allow easy, ongoing self-monitoring of their procedural process outcomes by the endoscopists. We did not have access to a database of general surgeons performing endoscopy in Canada and, therefore, did not survey most general surgeons, who are the primary providers of colonoscopy in rural Canada (21). Our survey results, therefore, are not representative of the practice patterns of the use of sedation and concomitant monitoring in these parts of the country. The present study was descriptive in nature and, because comparisons among groups were not prespecified, the comparisons performed are subject to the fallacies of post hoc analysis and multiple statistical testing. 


\section{CONCLUSION}

Results of the present survey suggest that most endoscopists in urban Canada use intravenous sedation for colonoscopy. However, there is a wide variation in sedation practice across the country, with propofol being used more frequently in Ontario. Although most endoscopists are quite satisfied with the sedative agents available to them, there is higher satisfaction among those using propofol for routine colonoscopies. With current staffing and monitoring practices in Canada, it may not be feasible to increase the routine use of propofol if current guidelines are to be followed. Further studies are needed to determine the optimal staffing of endoscopy units - with and without the use of propofol. In addition, sedation practices of general surgery endoscopists in Canada need to be better described.

ACKNOWLEDGEMENTS: The CAG provided support for the survey mailing to CAG members. Dr Singh is supported in part by an American College of Gastroenterology Junior Faculty Development Award. The authors have no financial disclosures or conflicts of interest to declare.

\section{REFERENCES}

1. Radaelli F, Meucci G, Sgroi G, Minoli G. Technical performance of colonoscopy: The key role of sedation/analgesia and other quality indicators. Am J Gastroenterol 2008;103:1122-30.

2. Aisenberg J, Cohen LB. Sedation in endoscopic practice. Gastrointest Endosc Clin N Am 2006;16:695-708.

3. Cohen LB, Wecsler JS, Gaetano JN, et al. Endoscopic sedation in the United States: Results from a nationwide survey. Am J Gastroenterol 2006;101:967-74.

4. Froehlich F, Harris JK, Wietlisbach V, Burnand B, Vader JP, Gonvers JJ. Current sedation and monitoring practice for colonoscopy: An International Observational Study (EPAGE). Endoscopy 2006;38:461-9.

5. Subramanian S, Liangpunsakul S, Rex DK. Preprocedure patient values regarding sedation for colonoscopy. J Clin Gastroenterol 2005;39:516-9.

6. Faulx AL, Vela S, Das A, et al. The changing landscape of practice patterns regarding unsedated endoscopy and propofol use: A national web survey. Gastrointest Endosc 2005;62:9-15.

7. Singh H, Poluha W, Cheung M, Choptain N, Baron KI, Taback SP. Propofol for sedation during colonoscopy. Cochrane Database Syst Rev 2008;(4):CD006268.
8. Bressler B, Paszat LF, Chen Z, Rothwell DM, Vinden C, Rabeneck L. Rates of new or missed colorectal cancers after colonoscopy and their risk factors: A population-based analysis. Gastroenterology 2007;132:96-102.

9. Rabeneck L, Rumble RB, Axler J, et al. Cancer Care Ontario Colonoscopy Standards: Standards and evidentiary base. Can J Gastroenterol 2007;21(Suppl D):5D-24D.

10. Shah HA, Paszat LF, Saskin R, Stukel TA, Rabeneck L. Factors associated with incomplete colonoscopy: A population-based study. Gastroenterology 2007;132:2297-303.

11. Baxter NN, Sutradhar R, Forbes SS, Paszat LF, Saskin R, Rabeneck L. Analysis of administrative data finds endoscopist quality measures associated with post-colonoscopy colorectal cancer. Gastroenterology 2011;140:65-72.

12. Kaminski MF, Regula J, Kraszewska E, et al. Quality indicators for colonoscopy and the risk of interval cancer. N Engl J Med 2010;362:1795-803.

13. Heuss LT, Froehlich F, Beglinger C. Changing patterns of sedation and monitoring practice during endoscopy: Results of a nationwide survey in Switzerland. Endoscopy 2005;37:161-6.

14. Cohen LB, Delegge MH, Aisenberg J, et al. AGA Institute review of endoscopic sedation. Gastroenterology 2007;133:675-701.

15. British Society of Gastroenterology. Safety and sedation during endoscopic procedures, 2003. <http://www.bsg.org.uk/clinicalguidelines/endoscopy/guidelines-on-safety-and-sedation-duringendoscopic-procedures.html> (Accessed on March 7, 2011).

16. Alharbi O, Rabeneck L, Paszat LF, et al. A population-based analysis of outpatient colonoscopy in adults assisted by an anesthesiologist. Anesthesiology 2009;111:734-40.

17. Vargo JJ, Cohen LB, Rex DK, Kwo PY. Position statement: Nonanesthesiologist administration of propofol for GI endoscopy. Gastroenterology 2009;137:2161-7.

18. Byrne MF, Chiba N, Singh H, Sadowski DC. Propofol use for sedation during endoscopy in adults: A Canadian Association of Gastroenterology position statement. Can J Gastroenterol 2008;22:457-9.

19. Lichtenstein DR, Jagannath S, Baron TH, et al. Sedation and anesthesia in GI endoscopy. Gastrointest Endosc 2008;68:815-26.

20. Kulling D, Orlandi M, Inauen W. Propofol sedation during endoscopic procedures: How much staff and monitoring are necessary? Gastrointest Endosc 2007;66:443-9.

21. Hilsden RJ, Tepper J, Moayyedi P, Rabeneck L. Who provides gastrointestinal endoscopy in Canada? Can J Gastroenterol 2007;21:843-6. 


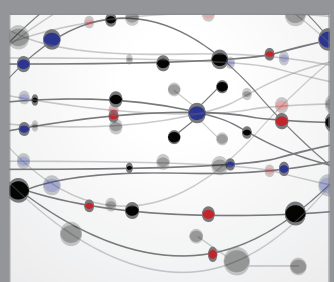

The Scientific World Journal
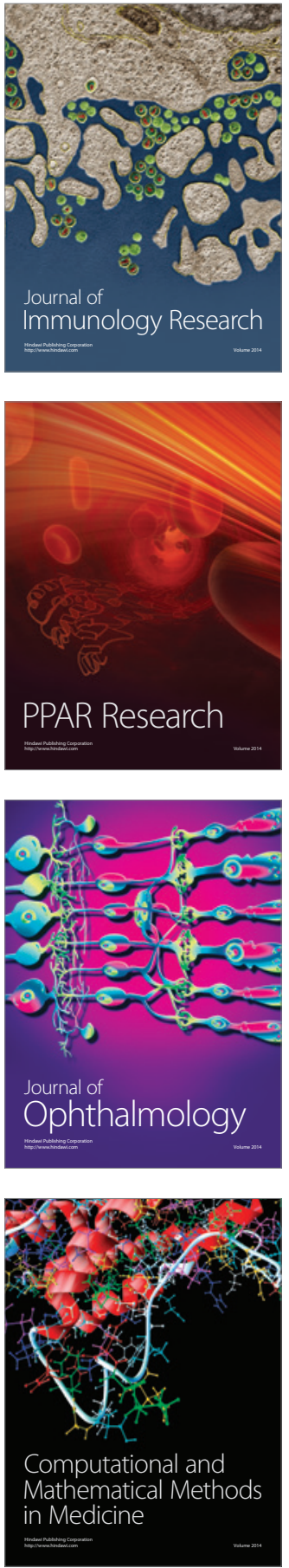

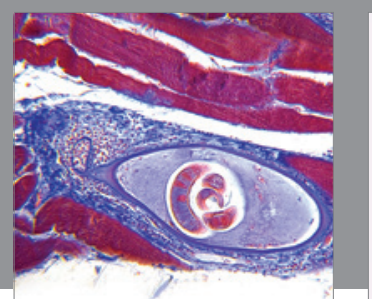

Gastroenterology Research and Practice

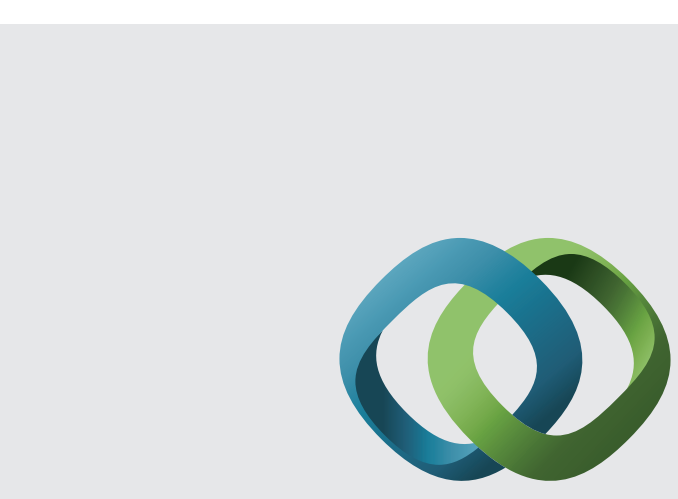

\section{Hindawi}

Submit your manuscripts at

http://www.hindawi.com
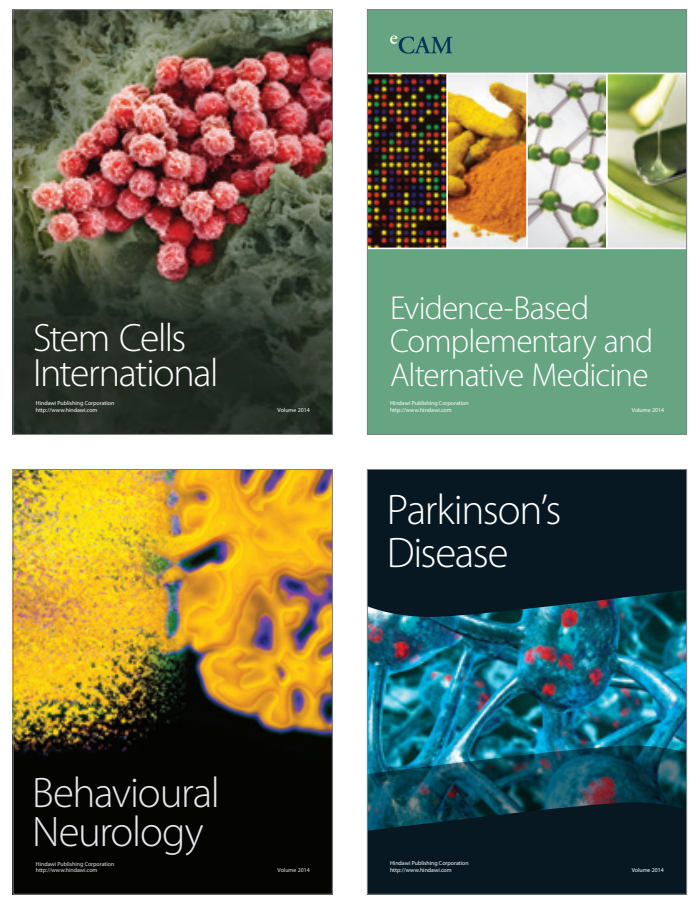
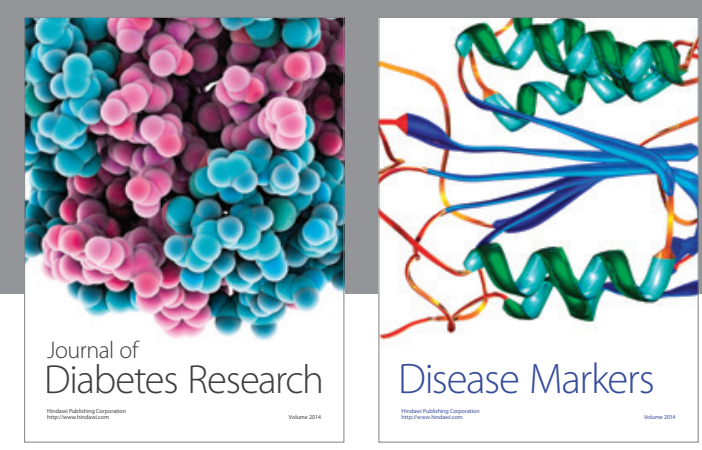

Disease Markers
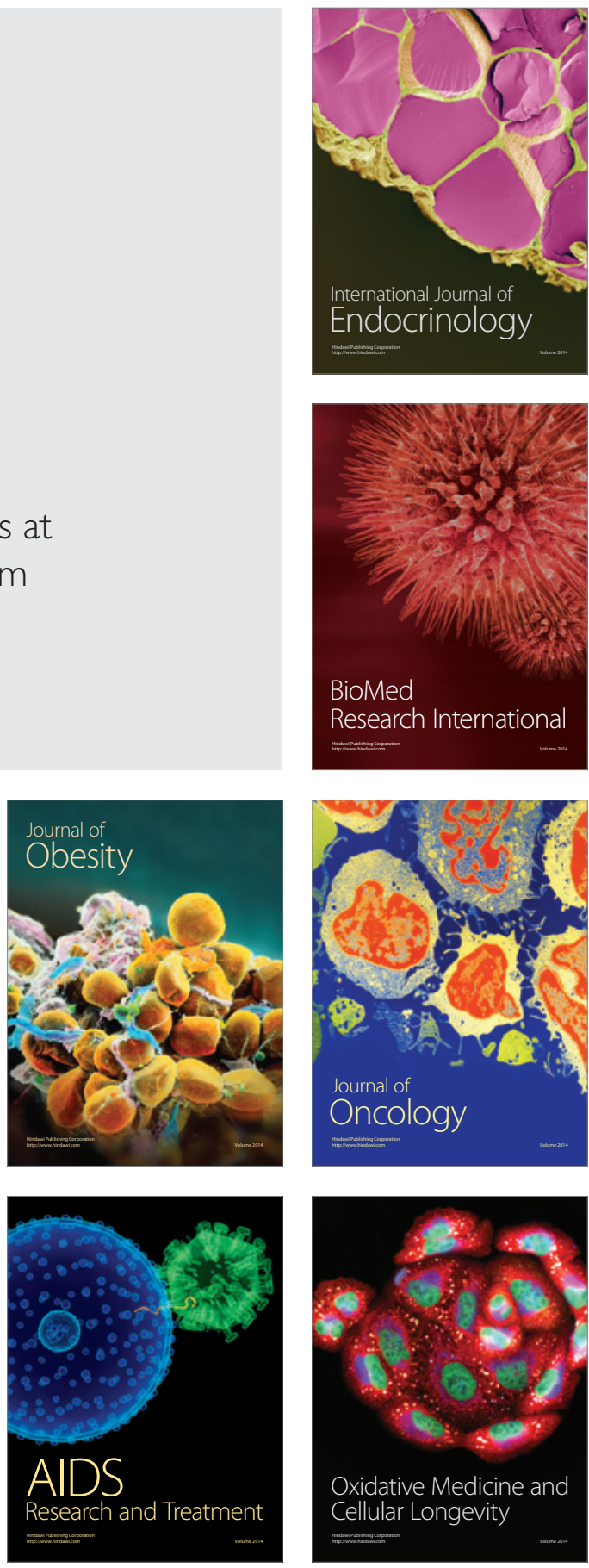